\title{
Manifesto pró-literatura portuguesa e por extenso
}

\author{
Saulo Gomes Thimóteo* \\ UFFS
}

\section{Professor de literatura portuguesa luso-brasileiro e tudo! ${ }^{1}$}

Fingir que a Literatura Portuguesa não contribuiu para a formação da cultura brasileira é como ignorar um membro da família. Ter como diretriz o diálogo e a multiculturalidade, mas omitir-se quanto a milenar cultura do povo português (que, bem ou mal, dialoga e interage diretamente com o Brasil) é uma contradição.

Por isso, desbastemos o que basto está!

\section{动 PAM}

Deve-se considerar a dimensão cultural possível da associação com um país “irmão de língua”.

Nas escolas da Argentina, Colômbia, Chile e demais países da América Latina, não se deve apresentar um personagem como Dom Quixote, e um autor como Cervantes, só porque vêm da Espanha, como se fosse uma metrópole tenebrosa e colonizadora ainda hoje?

Nos Estados Unidos, Shakespeare deveria ser nome nunca pronunciado, por vir de além do Atlântico, de um lugar que, desde as batalhas de George Washington, todo americano aprenderia a abominar?

Então, se tudo isso é um exagero e algo disparatado, porque o Brasil não possuirá abertura no Ensino Básico para que se apresente Luís de Camões, figura que se equipara aos autores supracitados? E que mesmo Harold Bloom, em sua obra “Gênio”, ao tratar dOs Lusíadas, comenta: “Embora o tema de Camões seja o heroísmo português, o poeta está sempre a contabilizar o custo humano de tudo o que relata, e a sua profunda ambivalência reflete um gênio tão compadecido quanto corajoso”.

Ou então ler Fernando Pessoa, português que muitos brasileiros parecem achar que nasceu no Brasil, se olharmos a $18^{\circ}$ posição do escritor brasileiro mais admirado, presente em “Retratos da Leitura no Brasil 2012”.

Ou o padre António Vieira, um português tão brasileiro que parece ter fundado uma nova língua, fluida, arquitetônica e belíssima.

Ou Almada Negreiros, muso inspirador deste texto, que se iguala a Oswald de Andrade na produção modernista do gênero literário Manifesto.

Ou ainda José Saramago, até o momento, o único escritor de língua portuguesa que recebeu o Nobel de Literatura, que em seus romances,
${ }^{*}$ Universidade

Federal da Fronteira

Sul, campus Realeza/

PR) sthimoteo@

gmail.com

${ }^{1}$ Se você entendeu a referência, agradeça a seu professor de literatura (portuguesa ou que com ela dialoga), se não, busque por José de Almada Negreiros e o Manifesto AntiDantas, que não se arrependerá. 
crônicas, peças, poemas, muito mais do que se restringir a Portugal, propõe um constante questionamento das "verdades imutáveis". Isso, ao que parece, também é algo que se entretece em todo o texto da BNCC. Por que perder tal diálogo, se o melhor seria incentivar a sua leitura?

\section{萦 $\mathrm{PEM}$}

Há uma intertextualidade evidente por toda a literatura brasileira.

Se uma das dimensões do “eixo leitura” (p. 37) é o desenvolvimento de estratégias de leitura, em que se propõe ativar conhecimentos prévios, apreender sentidos globais do texto e, sobretudo, estabelecer relações de intertextualidade, leiamos com um pouco mais de cuidado dois dos nossos principais autores: Machado de Assis e Guimarães Rosa.

Do primeiro, muito se perde, se não se incorporar, à leitura de Memórias Póstumas de Brás Cubas, as digressões aprendidas (ou apreendidas?) de Almeida Garrett; ou a peça teatral “Tu, só tu, puro amor”, claramente remetida a um verso dos Lusíadas, do episódio de Inês de Castro².

Do segundo, como falar do monumento que é Grande Sertão: Veredas, sem mencionar, nem ao menos de leve, a evocação do cancioneiro português e da "Donzela que vai à guerra”?

Só mais um:

E Ariano Suassuna, um dos mais representativos autores brasileiros (e com grandes raízes nesse solo), como dissociá-lo do teatro medieval de Gil Vicente visível em Auto da Compadecida e Farsa da boa preguiça, ou de todo o sebastianismo (português, ora pois) que se saboreia no Romance da Pedra do Reino e do Príncipe do Sangue do Vai-e-Volta?

\section{PIM}

A necessidade de uma incorporação da língua portuguesa como patrimônio cultural. Que a literatura portuguesa seja considerada, pelo menos em seus expoentes, da mesma forma que as literaturas dos países africanos de expressão portuguesa. Vivemos um momento histórico de grande abertura e como a própria BNCC diz, é necessário proporcionar aos alunos um "encontro com nossa diversidade linguística e cultural e ampliando a relação dos sujeitos com as culturas locais e universais” (p. 31). Mas como tal encontro é possível, se a própria cultura brasileira perde um pedaço de si ao esquivar seu olhar de um milênio da história portuguesa?

Chico Buarque, no jogo feito em “Fado tropical”, exemplifica um caminho possível: há uma irmanação, não uma equiparação entre Brasil e Portugal. E se é tão necessário o diálogo, tão almejado o intercâmbio, tão festejada a interação, por que não aproveitar, na Base Nacional Comum Curricular, a conversa naturalíssima que aflora dos países que falam português? Não como imposição de uma sobre a outra, mas a aproximação, com respeito às particularidades.

\footnotetext{
${ }^{2}$ Aliás, uma história com tanta magnitude e beleza como é a do amor de Pedro e Inês, simplesmente apagada, por não se querer contemplar os aspectos da literatura portuguesa, é algo, no mínimo, triste.
} 
Não se está sugerindo que se iguale o tratamento entre a Literatura Brasileira e a Portuguesa, mas essa última deve ser contemplada, ao menos por uma questão de lógica da língua.

Multilinguismo e transculturalidade (p. 36) são conhecimentos importantes? Então tenham em mente a língua portuguesa em sua constituição múltipla, global, bem como a cultura plural que a formou (e a forma). Portugal não possui um papel significativo em tal ação?

É importante ter em mente o que o crítico e historiador português Jaime Cortesão aponta como aspectos originais da literatura portuguesa: «a objetividade serena da observação, aliada a um poder sugestivo de narrar e a uma profunda compreensão do humano e do exótico - aquilo a que chamamos o humanismo universalista dos portugueses, capaz de alargar o sentido da dignidade humana pela experiência vivida de todos os povos e de todas as raças”. Diante disso não é necessário apresentá-la (e textualmente incluí-la) no BNCC? E, assim, apagar o perigo já apontado por Gilberto Freyre, na primeira metade do século XX, em sua conferência: "Uma cultura ameaçada: a luso-brasileira”. Não se solicita que se menosprezem as demais culturas que formaram o Brasil, mas incluir Portugal é um ato não só de razão, mas também de justiça.

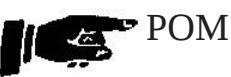

A recíproca não é verdadeira.

Em Portugal, nomes como Jorge Amado, José Lins do Rego, Clarice Lispector são estudados nas escolas, nos $10^{\circ}, 11^{\circ}$ e $12^{\circ}$ anos. Os livros didáticos portugueses trazem trechos inteiros dos romances brasileiros (sobretudo do Regionalismo de 30), na perspectiva de apresentar não uma literatura com a “cor local”, mas uma literatura que seja boa de ler - e em língua portuguesa!

A poeta brasileira por excelência, Cecília Meireles, foi reconhecida por sua poesia muito antes em Portugal, sendo deixada de lado durante boa parte do modernismo brasileiro.

Ou seja, um povo como o português, zeloso de sua cultura, sabe a importância que as demais culturas dos países de língua portuguesa têm para a formação de seus alunos. E o povo brasileiro? Julga que, ao fechar-se, afirma-se mais? Eis um caminho perigoso...

Algo muito grave acontece, quando alunos do Ensino Fundamental, outros do Ensino Médio, e até mesmo do Ensino Superior, possuem como única referência a Vasco da Gama o time carioca de futebol. O pecado é da História? Da Cultura? Se o discurso histórico apresenta o navegador, Camões, nOs Lusíadas, apresenta todo um povo através da linguagem.

\section{动 PUM}

Por uma revisão textual da linguagem empregada na BNCC:

Dentro dos objetivos gerais do componente curricular Língua 
Portuguesa na Educação Básica, existe o dúbio "Valorizar diferentes identidades sociais, lendo e apreciando a literatura das culturas tradicional, popular, afro-brasileira, africana, indígena e de outros povos e culturas” (p. 41). Eis aí todo o busílis, pois pensar que os “outros povos e culturas” contemplam Portugal é uma inclinação muito abstrata e superficial. Quem diz "outros povos”, nesse contexto, pode dizer as literaturas da Alemanha, do México, da África do Sul, da Índia, da Austrália, e também de Portugal. Mas, entre os romances de J. M. Coetzee e os de Eça de Queiroz, os desse último, a princípio, podem dialogar de mais perto com a tradição e cultura brasileira.

Por que não incorporar, no rol das culturas mencionadas, a portuguesa e, ao invés do adjetivo abrangente “africana”, acrescentar os demais membros da CPLP (Angola, Guiné-Bissau, Guiné Equatorial, Moçambique, Cabo Verde, São Tomé e Príncipe e Timor-Leste)?Ao se dizer que um dos objetivos gerais da área de Linguagem do Ensino Médio é “apropriar-se do patrimônio cultural, compreendendo a diversidade das culturas brasileiras e estrangeiras” (p. 36), por que não singularizar a cultura portuguesa, dos países africanos e indígena, como elementos primários do dito "processo de disputas e de legitimação de culturas”, havendo, por certo, elementos secundários, como todas as culturas dos povos imigrantes?

Nos objetivos de aprendizagem do componente curricular Língua Portuguesa no Ensino Fundamental, alguns itens tendem a reforçar o apagamento da cultura (e literatura) portuguesa, simplesmente por omiti-la.

Objetivos do Ensino Fundamental:Práticas artístico-literárias

$>$ LILP1FOA006, > LILP2FOA007, > LILP3FOA004, > LILP4FOA004, > LILP5FOA002 (com algumas nuances) - “Ler e apreciar textos literários tradicionais, da cultura popular, afro-brasileira, africana, indígena e de outros povos”.

Por que não, simplesmente, incluir a portuguesa? Já foi citada a beleza do Cancioneiro (de Garcia de Resende), em que, além da “Donzela que vai à guerra”, há outras como da "Bela infanta”, “A nau catrineta”, “A morte de Inês de Castro”. Não se pode dizer que essas histórias são melhores que as das mitologias tupi-guarani ou africanas, mas são tão belas e imaginativas quanto.

> LILP1FOA006 - “Ouvir e recitar parlendas...” Se há as parlendas, há as cantilenas portuguesas também, das quais muitas das nossas derivam... Mais uma vez, pergunta-se: Por que ocultar a origem?

> LILP4FOA005 - "Recontar fábulas, apropriando-se das características do texto fonte"

Em muitos lugares, quando se apresentam as fábulas de La Fontaine em verso, a tradução utilizada é de Manuel Maria Barbosa du Bocage, um português. Ele mesmo tendo criado algumas... 
> LILP6FOA009 - "Produzir poemas de gêneros variados, como haicais, sonetos...”.

Como pedir que os alunos (de $6^{\circ}$. Ano, mas vá lá!) produzam sonetos, se não é possível ter a oportunidade de ler nomes como Florbela Espanca, Antero de Quental, Bocage, Camões?

> LILP8FOA007 - "Reconhecer, no conjunto da produção poética da literatura endereçada a jovens e também da literatura brasileira, poemas que apontem a dimensão imagética, no uso de comparações, metáforas e metonímias”.

Por que restringir à literatura brasileira? Por que não "e também das literaturas de língua portuguesa”? Afinal, Fernando Pessoa e António Gedeão, por exemplo, são poetas produtores de alta carga imagética, metafórica e metonímica - além de trazerem consigo a aura do universal.

Objetivos do Ensino Médio: Práticas artístico-literárias

> LILP1MOA001 a > LILP1MOA003.

Não há menção alguma às produções portuguesas... Por que não criar um novo item, ou, pelo menos, acrescentar ao último a literatura portuguesa? Dessa forma, o projeto de "reconhecer a literatura como lugar de encontro de multiculturalidades” será mais acurado, pois omitir a cultura portuguesa é uma falha, pois mesmo nomes brasileiríssimos como Manuel Bandeira e Carlos Drummond de Andrade cantaram (e muito bem!) o poeta Luís de Camões.

\section{> LILP2MOA001}

Ler-se as produções literárias dos séculos XX e XIX é muito importante, e, no diálogo com o século XXI, muitas coisas podem surgir. Mas por que tirar nomes como José Saramago, Agustina Bessa-Luís, Miguel Torga, Fernando Pessoa, Florbela Espanca, Cesário Verde, Eça de Queiroz, Camilo Castelo Branco, Alexandre Herculano, dessa conversa? E também Mia Couto, Paulina Chiziane, José Craveirinha, Noémia de Souza? E também Pepetela, Agostinho Neto, Ondjaki, Ana Paula Tavares? Nossos alunos não são capazes de enxergar além-fronteiras?

\section{$>$ LILP3MOA001}

As produções dos séculos XVIII, XVII e XVI também possuem uma vasta gama de possibilidades de leitura e diálogo com a contemporaneidade, pois toda a base de nossa tradição vem de lá. Mas, no século XVI, quais eram as produções brasileiras? O "texto inaugural” do período chamado Quinhentismo foi escrito por um português: Pero Vaz de Caminha. Da mesma forma, muitas outras obras do período foram escritas por portugueses: Pero de Magalhães Gândavo; ou o jesuíta-santo José de Anchieta. Obras como a de Frei Vicente do Salvador, embora de alto valor histórico, não creio que seriam largamente trabalhadas nas aulas de língua portuguesa... E se vai esquecer toda a poesia de Bocage? A obra lírica e épica de Camões? 
O teatro vicentino? A poesia palaciana, a demanda do Santo Graal e toda a lírica trovadoresca? Por quê? Para nos chamarmos "nacionalistas"? Sabemos que essa palavra é problemática...

Com base em tudo isso, e para evitarmos um derramamento desnecessário de lágrimas literárias luso-brasileiras, bastam cinco ações:

1) Basta abrir caminho além do Bojador: para que o envolvimento com uma cultura tão próxima que parece nossa seja valorizado; para que o trabalho com o texto literário não seja tolhido de importantes obras atemporais e universais; para que a língua portuguesa seja contemplada, realmente, como o caleidoscópio que é. PAM!

2) Basta permitir que a riqueza dos diálogos intertextuais seja desenvolvida em sua mais plena força. E que se ouçam o concerto de Machado com Eça, o do Regionalismo do século XX com o Neorrealismo, ou o da sinfonia barroca luso-brasileira que é o padre António Vieira. PEM!

3) Basta incluir na BNCC a literatura e a cultura portuguesa (sugestões acima). Não se está pedindo que toda a Educação Básica leia “A Ceia dos Cardeais”, do Júlio Dantas, e ignorem a literatura brasileira. Está-se pedindo a chance de trabalhar a literatura do Brasil nos diálogos possíveis e ricos com a literatura de Portugal. N PIM!

4) Basta retribuir o cuidado que Portugal possui com o que de melhor se produziu (e produz) aqui, mostrando aos nossos alunos as produções lusófonas num sentido global. Isso nunca deve ser entendido como um rebaixamento ao status de ex-colônia, mas sim como países irmãos que buscam a valorização da língua portuguesa que, mesmo diferente, nos une a todos. POM!

5) Basta rever o texto da BNCC, e não cair na autocontradição de querer ser polifônico, sem ouvir a guitarra portuguesa. PUM!

Baste a quem baste o que lhe basta o bastante de lhe bastar... Mas nosso povo é um povo criativo, curioso e que só tem a ganhar atravessando esse rio chamado Atlântico e reconquistando e reconhecendo-se em Portugal.

Não retirem essa oportunidade de nossos professores! Não privem desse conhecimento os nossos alunos!

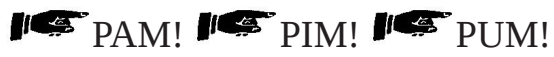

